\title{
Structure and Properties of DLC Films Deposited on Mg Alloy at Different $\mathrm{C}_{2} \mathrm{H}_{2}$ Flows of Magnetron Sputtering Process
}

\author{
Haitao $\mathrm{Li}^{1,2, * \mathbb{D}}$, Pengfei Sun ${ }^{3, *}$ and Donghai Cheng ${ }^{1}$ \\ 1 College of Aeronautical Manufacturing Engineering, Nanchang Hangkong University, Nanchang 330063, \\ China; 70802@nchu.edu.cn \\ 2 College of Material Science and Engineering, Jilin University, Changchun 130025, China \\ 3 College of Material Science and Engineering, Jiamusi University, Jiamusi 154007, China \\ * Correspondence: haitao0204@126.com (H.L.); liht13@mails.jlu.edu.cn (P.S.); Tel.: +86-791-83863030 (H.L.)
}

check for

updates

Citation: Li, H.; Sun, P.; Cheng, D. Structure and Properties of DLC Films Deposited on $\mathrm{Mg}$ Alloy at Different $\mathrm{C}_{2} \mathrm{H}_{2}$ Flows of Magnetron Sputtering Process. Coatings 2021, 11, 815. https://doi.org/10.3390/ coatings 11070815

Received: 14 June 2021

Accepted: 4 July 2021

Published: 6 July 2021

Publisher's Note: MDPI stays neutral with regard to jurisdictional claims in published maps and institutional affiliations.

Copyright: (c) 2021 by the authors. Licensee MDPI, Basel, Switzerland. This article is an open access article distributed under the terms and conditions of the Creative Commons Attribution (CC BY) license (https:// creativecommons.org/licenses/by/ $4.0 /)$.

\begin{abstract}
Diamond-like carbon (DLC) film is widely used due to its excellent properties, such as high hardness and high wear resistance. To investigate the advantages of DLC film applied on the surface of $\mathrm{Mg}$ alloy, direct current (DC) pulse magnetron sputtering was used to prepare DLC film via plasma sputtering a graphite target and introducing $\mathrm{C}_{2} \mathrm{H}_{2}$ gas. The silicon interlayer was fabricated by sputtering the Si target. A scanning electron microscope (SEM), transmission electron microscope (TEM), a nano-indentation instrument, an electrochemical workstation and a pin-on-disc tester were employed to obtain the surface morphology, microstructure, mechanical properties, corrosion behavior and wear resistance of the obtained film, respectively. The results show that the DLC films are dense and compact, and the structure changes from amorphous to nanocrystalline with the increase of $\mathrm{C}_{2} \mathrm{H}_{2}$ flow. The film prepared at low $\mathrm{C}_{2} \mathrm{H}_{2}$ flow has larger surface roughness, lower deposition rate, higher hardness and elasticity modulus, poorer corrosion resistance and better wear resistance, compared with the film prepared at higher acetylene flow. The self-corrosion potential of the obtained DLC film is higher than $-0.95 \mathrm{~V}$, the corrosion current density is $10^{-7} \mathrm{~A} / \mathrm{cm}^{2}$ orders of magnitude, and the wear rate is $10^{-9} \mathrm{~mm}^{3} / \mathrm{Nm}$ orders of magnitude. The friction coefficient of the film is less than 0.065 , the hardness is 17.3 to $22.1 \mathrm{MPa}$, and the elastic modulus is 145 to $170 \mathrm{MPa}$. The DLC films obtained on the surface of AZ91 alloy have good comprehensive properties.
\end{abstract}

Keywords: DLC film; wear resistance; corrosion; magnetron sputtering; Mg alloy

\section{Introduction}

Diamond-like carbon (DLC) is an amorphous carbon material composed of $\mathrm{sp}^{2}$ and $\mathrm{sp}^{3}$ hybridized carbon atoms. DLC film has attracted much attention as a versatile material owing to its excellent properties such as corrosion resistance, high mechanical hardness, high electrical insulation, high thermal conductivity, as well as its good tribological properties [1-6]. For example, Ding et al. [7] deposited DLC coating on the Ti-6Al-4V substrate using the plasma-assisted chemical vapor deposition (PACVD) technique. They found that the coating presented high adhesion when a Si-rich interlayer with the thickness of approximately $0.5 \mu \mathrm{m}$ was used as a bonding layer. Wang et al. [8] investigated the uniformity, mechanical and tribological properties of the thick Si/Si-DLC/DLC multilayer at different working pressures, the results show that the DLC coatings prepared by plasma enhanced chemical vapor deposition (PECVD) technology present good tribological properties and high hardness. Lan et al. [9] produced DLC coating on Cr12MoV steel by an in-situ duplex plasma nitriding and arc ion plating (AIP) process, which also indicated the high performance of the obtained DLC coating. Zhang et al. [10] used magnetron sputtering (MS) to prepare four different types of DLC coatings including amorphous carbon $(\mathrm{a}-\mathrm{C})$ and amorphous carbon doped with $\mathrm{Si}(\mathrm{a}-\mathrm{C}(\mathrm{Si})), \mathrm{Al}(\mathrm{a}-\mathrm{C}(\mathrm{Al}))$ and $\mathrm{H}(\mathrm{a}-\mathrm{C}: \mathrm{H})$, respectively, on polished silicon wafers. They pointed out that the COF (coefficient of friction) of DLC coatings/PAO (poly-alpha-olefin) systems reduced by $19 \%-22 \%$, and the 
wear rate of all DLC coatings decreased by $2-3$ orders of magnitude. The composite of tribofilm was decided by the doped elements in DLC coatings. The doped element $\mathrm{H}$ led to the lowest wear rate of the a-C:H coating.

It can be known from above literature that DLC film can be formed on a variety of metals in a variety of methods to protect the substrate and improve its surface properties [11-17]. Compared with other techniques, magnetron sputtering has the characteristics of low temperature deposition, which is especially suitable for the preparation of protective DLC film on the surface of Mg alloy. It is well known that $\mathrm{Mg}$ alloy particularly needs to be protected due to the active Mg element and its low surface hardness. However, the major drawback for applying magnetron sputtering to the growth of films on the surface of $\mathrm{Mg}$ alloy is the low deposition rate. Because at a low temperature, the deposited atoms on the surface of substrate have poor diffusion and migration, the deposition rate is low and a longer time is required to deposit the thick coating. Moreover, the adhesion between the DLC coating and the Mg alloy is weak due to the larger difference in physical properties. In practice, we found it was difficult to deposit the DLC coating on the surface of $\mathrm{Mg}$ alloy. Even if it can be successfully deposited, it is also difficult to predict the structure and performance of the coating after deposition.

To protect the $\mathrm{Mg}$ alloy and improve its surface performance, and expand the application of $\mathrm{Mg}$ alloy in the aviation field, DLC film was deposited on the surface of the $\mathrm{Mg}$ alloy to achieve surface modification. The performance of DLC coatings is dependent on the deposition technique [7], which determines their structure. Therefore, the systematic investigation of DLC films fabricated via a mixed carbon source (graphite and $\mathrm{C}_{2} \mathrm{H}_{2}$ ) has been studied and compared in this work. Pulsed bias magnetron sputtering was used to improve the sputtering rate, adhesion and structure of the coating. The purpose of this work is to obtain many of the properties of DLC film, which was achieved via sputtering the mixed carbon sources. The structure, hardness, corrosion behavior, and wear resistance of the obtained DLC films were investigated.

\section{Materials and Methods}

Prior to deposition, all AZ91 specimens measuring $20 \times 20 \times 3 \mathrm{~mm}^{3}$ were ground by using grade 500, 800, 1000, 1500, and 2000 grit emery papers to obtain a smooth surface. Then, all the AZ91 samples were soaked in acetone, anhydrous ethanol and cleaned ultrasonically for $10 \mathrm{~min}$ and washed using deionized water [15,18]. The samples were then dried by blowing pure compressed $\mathrm{N}_{2}$ and placed on the holder of the coating equipment. The distance from the substrate to the target was fixed at $60 \mathrm{~mm}$. To obtain the micro-convex structure of the AZ91 surface, which enhances the locking effect between the substrate and the film, the AZ91 was etched for $30 \mathrm{~min}$ in a pure Ar plasma flowing at $80 \mathrm{sccm}$ under a bias voltage of $-1.0 \mathrm{KV}$, thus improving the adhesion of the film. To further improve the adhesive strength, an adhesion-promoting Si interlayer was first deposited to mitigate residual stress by applying a DC pulse power to sputter the pure Si target for 5 min with an Ar flow rate of $80 \mathrm{sccm}$, a DC pulse power of $280 \mathrm{~W}$, a frequency of $30 \mathrm{kHz}$, and a bias of $-100 \mathrm{~V}$. The first group of DLC films was prepared by sputtering graphite in an atmosphere of argon, and named G1. The second and the third groups were prepared in a mixture atmosphere of $\mathrm{Ar}$ and $\mathrm{C}_{2} \mathrm{H}_{2}$, and named $\mathrm{G} 2$ and $\mathrm{G} 3$, respectively. The process parameters are shown in Table 1.

A scanning electron microscope (SEM, FEI, Hillsboro, OR, USA) was employed to observe the surface and cross-sectional morphology. A transmission electron microscope (TEM, FEI, Hillsboro, OR, USA) was used to examine the microstructure on the surface of the coatings. The selected area electron diffraction (SAED) was applied to further investigate the microstructure information. The surface hardness was measured using a nanoindenter (KLA-Tencor, Milpitas, CA, USA) equipped with a diamond Berkovich indenter tip. Five valid measurements were performed to minimize error [19]. The indentation depth was approximately $1 / 10$ of the coating thickness in order to avoid the influence of the substrate. A pin-on-disk tester (SFT-2M, Lanzhou Institute of Chemical Physics, 
Chinese Academy of Sciences, Lanzhou, China) was used to evaluate the friction coefficient and wear resistance of the coatings under the condition of dry sliding against a $6 \mathrm{~mm}$ diameter $\mathrm{Al}_{2} \mathrm{O}_{3}$ ball rotating at $300 \mathrm{rpm}$ (at room temperature and relative humidity of $40 \%$ ). A normal load of $200 \mathrm{~g}$, a test duration of $10 \mathrm{~min}$, and the wear track morphology was observed with an optical microscope (OM, CR 30-T1000, suzhou bete jia optoelectronic technology co., LTD, Suzhou, China). An electrochemical workstation (Ametek, Berwyn, IL, USA) was used to evaluate the corrosion behavior of the DLC coatings in a $3.5 \mathrm{wt} \% \mathrm{NaCl}$ solution. The experimental set-up comprised a three-electrode arrangement with a Pt sheet as a counter electrode, a saturated calomel electrode (SCE) as a reference electrode, and the coatings as working electrodes. A polarization scan was performed at a rate of $1 \mathrm{mV} / \mathrm{s}$; after a steady-state potential was allowed to develop, the potential range was $-0.5 \mathrm{~V}_{\mathrm{ECS}}$ to $+0.5 \mathrm{~V}_{\mathrm{ECS}}[20,21]$. Electrochemical impedance spectroscopy (EIS) was executed at a disturbing potential of $10 \mathrm{mV}$ over the frequency range of $10^{4}$ to $0.01 \mathrm{~Hz}$.

Table 1. The process parameters of DLC film preparation.

\begin{tabular}{cc}
\hline Process and Operation & Values \\
\hline DC pulsed magnetron sputtering & $280 \mathrm{~W} ; 30 \mathrm{kHz} ;$ duty cycle of $50 \%$ \\
Bias $(\mathrm{V})$ & -100 \\
Working pressure $(\mathrm{Pa})$ & $0.5 \sim 1.0$ \\
Flow of $\mathrm{Ar}(\mathrm{sccm})$ & 80 \\
Flow of $\mathrm{C}_{2} \mathrm{H}_{2}(\mathrm{sccm})$ & $0(\mathrm{G} 1) ; 10(\mathrm{G} 2) ; 20(\mathrm{G} 3)$ \\
Deposition temperature $\left({ }^{\circ} \mathrm{C}\right)$ & 200 \\
Deposition time (min) & 85 \\
\hline
\end{tabular}

\section{Results and Discussion}

\subsection{Morphology}

Figure 1 shows the surface morphology of the DLC films. The top view image of Figure 1a indicates the G1 type of coating is compact, but is not flat, with the irregular globular aggregates of $0.8 \sim 2 \mu \mathrm{m}$ features, separated by very compact boundaries. It looks like cauliflower, and is often called cauliflower-type. The formation of so-called cauliflower morphology, that is typical for films deposited by magnetron sputtering, is a consequence of the atomic shadowing effect [3]. Figure $1 \mathrm{~b}$ exhibits that the G2 type of coating is not only compact but also smoother than the G1 type of coating, with the more uniform size of $0.1 \sim 0.5 \mu \mathrm{m}$. Figure 1c shows the SEM image of the G3 type of coating. As we can see, the G3 coating is composed from compact globular aggregates. However, its surface looks smoother. The dimension of the agglomerates is considerably reduced, G3 coating presents the smallest agglomerate particles of the three types. It indicates that the acetylene flow rate has a significant effect on the morphology and particle size of the film. With the increase of the acetylene flow rate, the particle size of the film decreases and the surface becomes more uniform and smoother. However, the effect of acetylene on the compactness of the film is not significant, although the characteristics of the globular aggregates of all coatings remain similar.
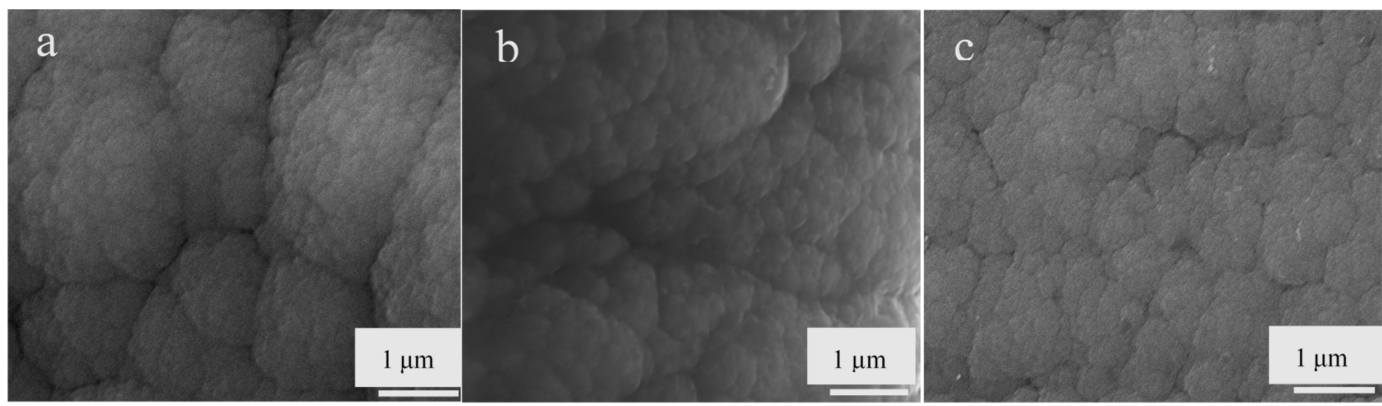

Figure 1. SEM images of the surface of coatings (a) G1; (b) G2; and (c) G3. 
Figure 2 shows the fracture cross-sectional SEM images of the DLC coatings. The thicknesses of the films were measured from the cross-section SEM images. As shown in Figure 2, the cross-section micrographs of the obtained films display a dense microstructure with a uniform thickness, and the interface between the layers is closely bonded. The total thickness of the two groups of coatings is $2.67 \mu \mathrm{m}$ (G1 type of coating) and $3.17 \mu \mathrm{m}$ (G3 type of coating), respectively. Based on the relationship between deposition time and film thickness, the deposition rates of the films were calculated to be $28.7 \mathrm{~nm} / \mathrm{min}$ for the G1 type of coating, and $34.1 \mathrm{~nm} / \mathrm{min}$ for the G3 type of coating. With the increase of the acetylene flow rate, the deposition rate of the film increases, mainly because the active acetylene gas is easy to ionize.
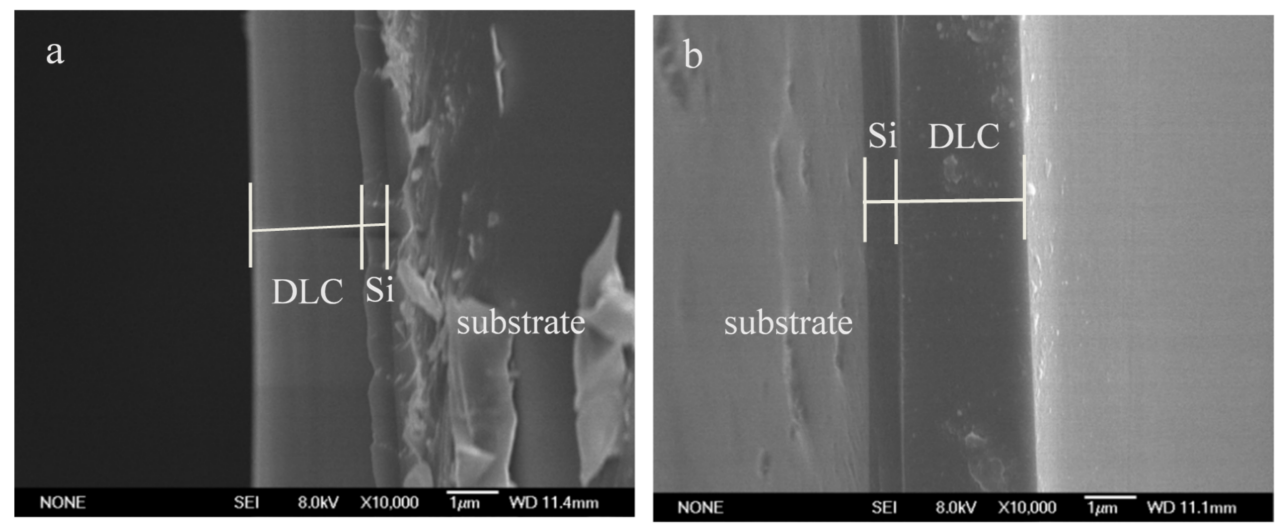

Figure 2. SEM images of fracture cross sections (a) G1; and (b) G3.

\subsection{Microstructure}

A high-resolution TEM image of the DLC coatings is presented in Figure 3. The corresponding SAED images are also displayed in Figure 3. Figure 3a,b exhibit the amorphous morphology, and the corresponding SAED images present the typical features of a halo, as shown in Figure 3d,e, further indicating the amorphous structure of the DLC film. However, Figure $3 \mathrm{c}$ presents the mixed structure of amorphous and nanocrystalline, and the distinct lattice fringes with small interplanar spacing can be clearly seen, as shown by the orange arrows. The corresponding SAED image in Figure $3 \mathrm{f}$ shows some regularly arranged diffraction spots in addition to the amorphous halo. It can be seen that the G3 type of coating is a fine single crystal, which is encapsulated by a surrounding amorphous structure. With the help of Digital Micrograph software, the length of 10 lattice stripes was measured in the enlarged area, as shown in the circled position in Figure 3c. Then, the measured length was divided by 10 to obtain the crystal plane spacing of 1.93 and 1.67 $\AA$, respectively. The corresponding crystal plane indices are (301) and (105), respectively, as shown at point A and point B in Figure 3f. Figure 3 indicates that with the increase of acetylene flow, the structure of DLC coating changes from fine amorphous to coarse amorphous, and then to fine nanocrystalline.

\subsection{Mechanical Properties}

The values of hardness $(\mathrm{H})$, elastic modulus $(\mathrm{E})$, plastic index parameter $(\mathrm{H} / \mathrm{E})$, and $\mathrm{H}^{3} / \mathrm{E}^{2}$ are often used to determine the mechanical properties of samples [14]. The $\mathrm{H}, \mathrm{E}$, $\mathrm{H} / \mathrm{E}$, and $\mathrm{H}^{3} / \mathrm{E}^{2}$ of the DLC films are shown in Table 2. As presented in Table 2, the G1 type of coating exhibits the highest hardness and elastic modulus of all the DLC films. The hardness values of the three films are 22.1, 20.3 and 17.4 GPa, respectively. The elastic modulus values are 168, 156 and $145 \mathrm{GPa}$, respectively. It is generally accepted that the wear resistance of a solid can be adjusted either by increasing $\mathrm{H}$ or decreasing $\mathrm{E}$ [22]. The $(\mathrm{H} / \mathrm{E})$ value can be used to explain elastic-plastic characteristics and predict the wear resistance of the films, the endurance capability $(\mathrm{H} / \mathrm{E})$ and resistance to plastic deformation $\left(\mathrm{H}^{3} / \mathrm{E}^{2}\right)$ displayed in Table 2. Table 2 exhibits that the G3 type of coating has the smallest hardness and elastic modulus of all the films, whereas the G1 type has the highest hardness 
and elastic modulus of all. This indicates that G1 type of coating has the lowest wear rate and the best wear resistance due to the highest $\mathrm{H} / \mathrm{E}$ ratio. In addition, a low $\mathrm{H} / \mathrm{E}$ ratio indicates elastic-plastic behavior, whereas a high ratio indicates elastic behavior $[1,23]$.
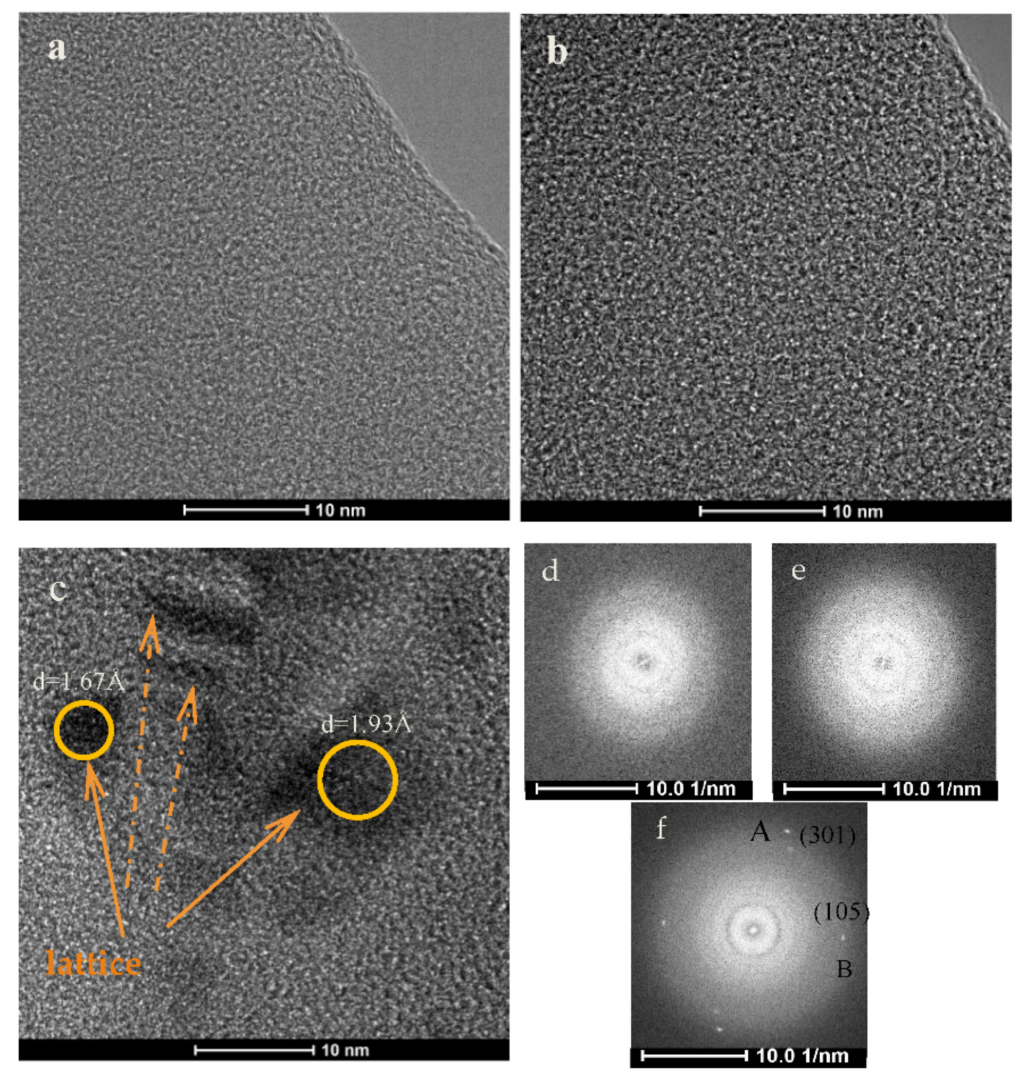

Figure 3. TEM surface morphology and the corresponding SAED images (a,d) G1; (b,e) G2; and (c,f) G3.

Table 2. Mechanical properties of the DLC films.

\begin{tabular}{ccccc}
\hline Coatings & H/GPa & E/GPa & H/E & $\mathbf{H}^{\mathbf{3} / \mathbf{E}^{2}}$ \\
\hline G1 & 22.1 & 168 & 0.13 & 0.38 \\
G2 & 20.3 & 156 & 0.13 & 0.34 \\
G3 & 17.4 & 145 & 0.12 & 0.25 \\
\hline
\end{tabular}

\subsection{Corrosion Behavior}

Figure 4a exhibits the potentio-dynamic polarization curves which can give us information about the anticorrosive protection abilities of the coatings [24]. The electrochemical parameters obtained from the potentio-dynamic polarization curves are shown in Table 3. Figure 4 a shows that the polarization curve of the DLC film has a large shift in the direction of decreasing the current density and increasing the potential compared to the AZ91 substrate. The polarization curves for the two DLC films exhibit similar shapes in the cathode reaction region. However, the self-corrosion potential $\left(E_{\mathrm{corr}}\right)$ of the G3 type of coating is slightly higher than that of the G2 type of coating, and the G2 type of coating is higher than the self-corrosion potential of the G1 type of coating. The corrosion current density $\left(I_{\text {corr }}\right)$ of the G1 type of coating in the anode reaction region is obviously higher than that of the G2 type and G3 type, indicating the G1 type of coating has the poorest corrosion resistance of the three. That is because the G1 type could be destabilized with anodic polarization and contribute to the current response in the curve of Figure 4a [25]. Therefore, the gradual increase in current during anodic polarization is a contribution of the DLC instability itself, 
i.e., the oxidation/dissolution of $\mathrm{C}$ within the DLC, or of the underlying $\mathrm{Si}$ interlayer at local DLC coating growth defects [26].
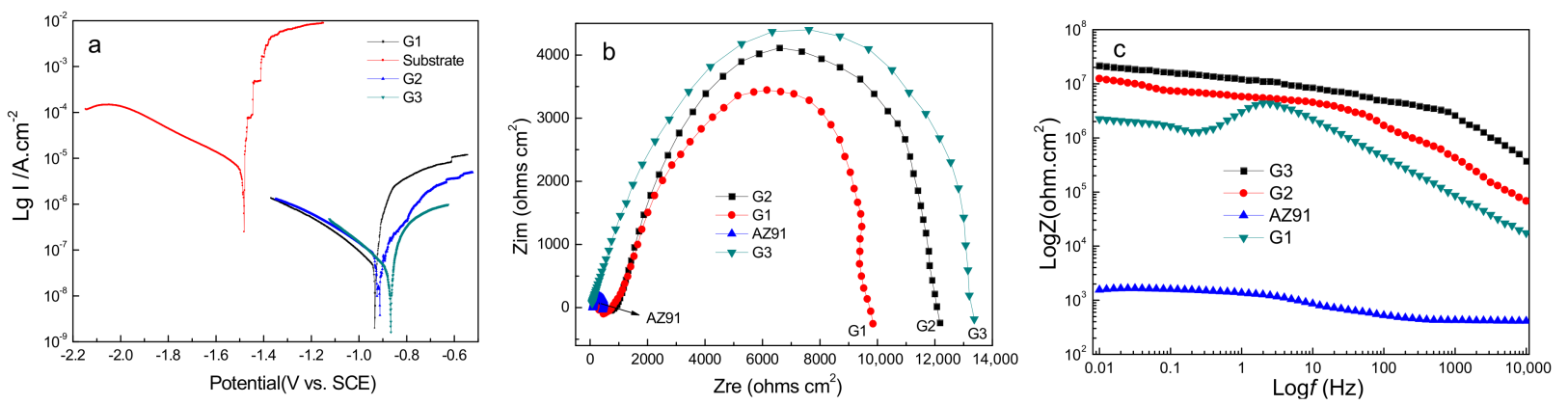

Figure 4. The results of electrochemical test (a) potentiodynamic polarization curves; (b) Nyquist plots; and (c) Bode plots of $|Z|$ vs. frequency.

Table 3. Potentio-dynamic polarization parameters of the samples.

\begin{tabular}{cccc}
\hline Samples & $\boldsymbol{E}_{\text {corr }}(\mathbf{V})$ & $\boldsymbol{I}_{\text {corr }}\left(\mathbf{A} \cdot \mathbf{c m}^{-2}\right)$ & $\boldsymbol{R}_{\text {corr }}(\mathbf{m m} /$ year $)$ \\
\hline AZ91 & -1.48 & $7.84 \times 10^{-4}$ & 17.77 \\
G1 & -0.94 & $8.31 \times 10^{-7}$ & 0.0188 \\
G2 & -0.90 & $5.15 \times 10^{-7}$ & 0.0117 \\
G3 & -0.88 & $3.94 \times 10^{-7}$ & 0.0089 \\
\hline
\end{tabular}

For additional evaluation of the corrosion resistance, the corrosion rate $\left(R_{\text {corr }}\right)$ of the film was calculated, using the following equation [27]:

$$
R_{\text {corr }}=3.268 \times I_{\text {corr }} \mathrm{M} / \mathrm{n} \rho
$$

where $I_{\text {corr }}$ is the corrosion current density, $\mathrm{M}$ is the molecular weight of the reacting substrate, $\mathrm{n}$ is the number of electrons exchanged, and $\rho$ is the density of materials [27].

As shown in Table 3, the self-corrosion potential of the DLC films is much higher than that of the substrate. The $E_{\text {corr values of }}-0.94 \mathrm{~V},-0.90 \mathrm{~V}$ and $-0.88 \mathrm{~V}$ were obtained for the G1, G2 and G3 films, respectively. The corrosion current density of the film is much lower (three orders of magnitude) than that of the substrate. The $I_{\text {corr }}$ of the G3 type of coating is the lowest of the three due to its fine nano-structure and smooth surface, implying the excellent corrosion resistance of the G3 type of coating. The corrosion rate of the G1, G2 and G3 films were estimated to $0.0188,0.0117$ and $0.0089 \mathrm{~mm} /$ year, respectively. The corrosion rate of bare substrate was estimated to $17.77 \mathrm{~mm} /$ year. It is obvious that the DLC coating very effectively protected the substrate against the electrochemical corrosion.

Figure $4 \mathrm{~b}$ presents the Nyquist plots of the samples. The Nyquist plots of the DLC films possess similar behavior, that the curves exhibit a single capacitive loop, indicating a typical capacitive response of the passive film [28]. The shape and diameter of the curves reflect the charge-transfer process and the corrosion resistance of the samples, respectively. Usually, a larger arc diameter of the capacitive loop corresponds to a higher corrosion resistance of the sample [29]. It can be clearly seen in Figure $4 \mathrm{~b}$ that the diameters of the capacitive loop of the coatings are much larger than that of the substrate, which demonstrates a better electrochemical performance of the coating in $\mathrm{NaCl}$ solution. The diameter of the capacitive loop for the G3 type of coating is the largest, indicating its strong corrosion resistance.

Figure 4c shows the Bode- $|Z|$ plots of the samples. Obviously, the $|Z|$ values of the DLC coating $\left(10^{7}\right)$ is four orders of magnitude higher than that of the substrate $\left(10^{3}\right)$, indicating the protective capability of passive films developed on the DLC coating is better than that of the substrate. It was well known that materials with a higher $\mathrm{Z}$ modulus at lower frequencies exhibited better corrosion resistance for metal substrates [21]. As shown 
in Figure 4c, the $\mathrm{Z}$ value of the G3 type of coating is higher than that of the G1 type and the G2 type due to the fine nano-stucture and smoother surface, indicating the best corrosion resistance. Figure 4c demonstrates that the DLC film could efficiently protect AZ91 from corrosion and the smooth surface would further enhance the corrosion resistance, which is in good agreement with the polarization curves and EIS plots in Figure 4a,b.

\subsection{Tribological Property}

Figures 5 and 6 show the friction coefficient, wear rate and wear track of the DLC coatings. As shown in Figure 5a, it can be observed that the low friction coefficient has been achieved, the friction coefficient of the G1 type of coating is stable at the beginning stage, then it remains stable, and the average value is approximately 0.032 . This is mainly due to the fact that the G1 type of coating has a relatively low hardness and $\mathrm{H} / \mathrm{E}$ value. However, the friction coefficient of the G2 type of coating has a different tendency; the friction coefficient increases first, then decreases, and after $50 \mathrm{~s}$ the friction process enters in a steady-state regime and the average value is approximately 0.045 . This is related to the surface roughness and the formation of the transfer layer. In the running-in stage, a mechanical locking effect was formed between the $\mathrm{Al}_{2} \mathrm{O}_{3}$ ball and the surface of the DLC coating. With increasing sliding time, the so-called cauliflower-type macro-particles were torn and fractured from the surface by shearing force and the surface became smoother. At the same time, a transfer layer between the two contact surfaces is formed. It has a very low shear strength [30]. Therefore, in the second stage, the friction coefficient decreased rapidly to a steady-stage value. The friction coefficient of the G3 type of coating increases significantly at first, and then slowly. Then the friction coefficient tends to be stable with small fluctuation, and the friction process is very stable with a value of about 0.06 .
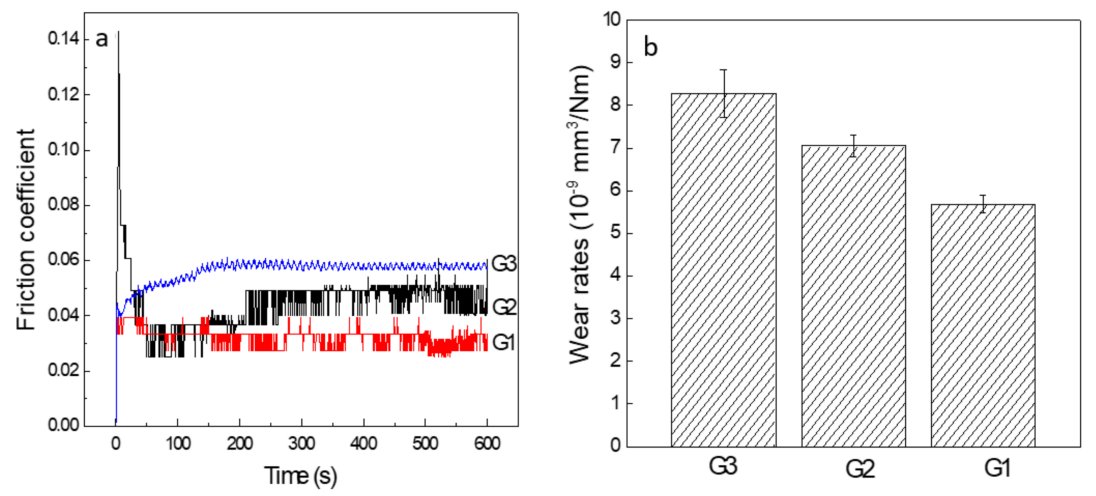

Figure 5. (a) Friction coefficients of the DLC films and (b) wear loss rates of the DLC films.

The wear rate $(\mathrm{W})$ of the coatings was calculated by Archard's classical wear equation [10]:

$$
\mathrm{W}=(\mathrm{C} \times \mathrm{S}) /(\mathrm{F} \times \mathrm{L})
$$

where $C$ is the perimeter of the wear scar, $S$ is the cross sectional area of the wear scar, $\mathrm{F}$ is the applied load and L is the total sliding distance. All the deposited DLC films present relatively low wear rates, as shown in Figure 5b. The wear rates of the G1, G2, and G3 types of coatings were calculated to be $5.69 \times 10^{-9}, 7.05 \times 10^{-9}$ and $8.28 \times 10^{-9} \mathrm{~mm}^{3} / \mathrm{Nm}$, respectively. It is noted that the wear rate of G1 is the smallest of the three due to the relatively higher hardness.

Figure 6 shows the typical optical microscopy images of the wear tracks obtained after the pin-on-disk test. As exhibited in Figure 6, there are no obvious peeling at the edge of the wear tracks, and the tracks are smooth. The smooth wear track with shallow scratch lead to both low friction coefficient and wear rate. It can be seen that the track on the surface of G1 type is shallower than that of the G2 and G3 types, and the width of the G1 type of coating is slightly narrower than that of the G2 and G3 types, implying that the G1 type possesses the better wear resistance. In addition, Figures 5 and 6 also imply that 
the hardness of the coating prepared by sputtering of graphite is higher than the coating fabricated by adding acetylene.
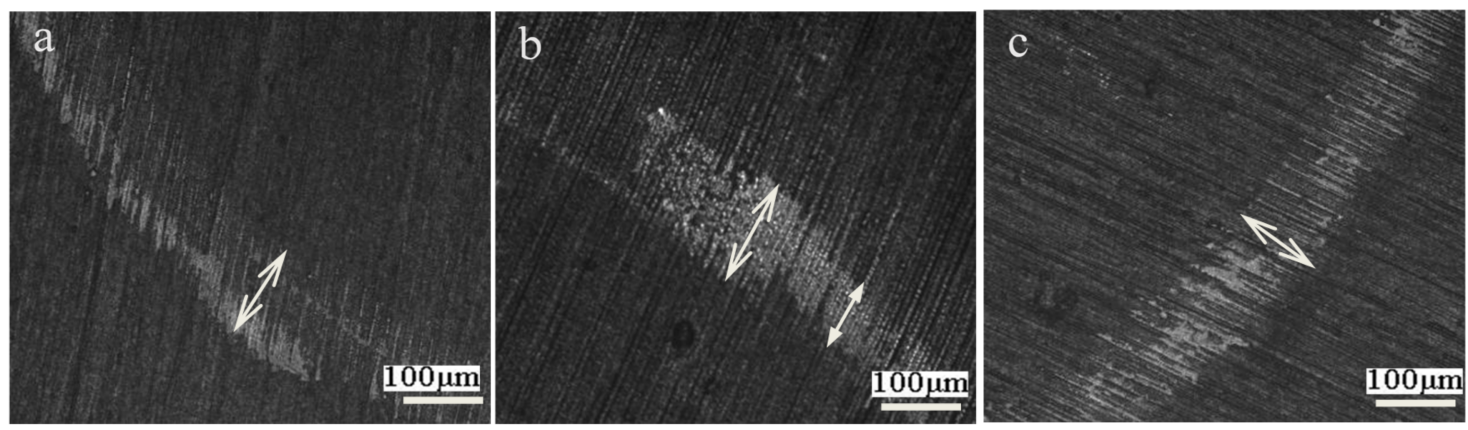

Figure 6. 2D profiles of the wear tracks observed by OM (a) G1; (b) G2; and (c) G3.

\section{Conclusions}

The DC-pulse magnetron sputtering is suitable for the preparation of DLC film on $\mathrm{Mg}$ alloy due to the low deposition temperature. However, reports on DLC films deposited on $\mathrm{Mg}$ alloy via composite carbon source are rare. We found that the structure of the DLC film deposited by DC-pulse magnetron sputtering on the surface of $\mathrm{Mg}$ alloy was compact and amorphous when the acetylene flow was low. But when the flow rate of acetylene exceeds $10 \mathrm{sccm}$, the structure of the film changes from amorphous to nanocrystalline. The amorphous structure is beneficial to the improvement of wear resistance, but the nanocrystalline helps to improve the corrosion resistance. The friction coefficient of the G3 type of coating is less than 0.065 , which is smaller than that of the TiC/a-C:H nanocomposite film prepared on Si wafer by the same method [31]. The average friction coefficient of our investigation is also smaller than that of the Cr/CrN/DLC film (the minimum is 0.14) synthesized on high speed steel via the same method [32]. The hardness and elastic modulus of our investigation are higher than that of the $\mathrm{Cr} / \mathrm{CrN} / \mathrm{DLC}$ film in reference [32] (hardness: from 5.72 to $8.02 \mathrm{GPa}$; elastic modulus: from 80.19 to $139.63 \mathrm{GPa}$, respectively), although our study and literature [32] display the same characteristics of an amorphous structure. Moreover, the DLC films in this paper also present good corrosion resistance performance, and a certain toughness. This paper proves that carbon source is the decisive factor of the performance of DLC film. Acetylene has a great beneficial effect on the corrosion resistance. We found that the good corrosion resistance and good wear resistance cannot be achieved simultaneously.

Author Contributions: H.L.: conceptualization, data curation, resources, writing—original draft; P.S.: methodology, writing - review and editing; D.C.: investigation, formal analysis. All authors have read and agreed to the published version of the manuscript.

Funding: This work was financially supported by the Doctoral Research Initiation Project of Nanchang Hangkong University (No. EA201903408) and the Project of Young Talents Innovation Program of Heilongjiang Provincial Education Department (Grant No. UNPYSCT-2017147).

Institutional Review Board Statement: Not applicable.

Informed Consent Statement: Not applicable.

Data Availability Statement: All data has been shown in this manuscript.

Acknowledgments: The authors acknowledge the Analysis and Testing Center, Nanchang Hangkong University, for providing assistance of microstuctural characterization.

Conflicts of Interest: The authors declare no conflict of interest.

\section{References}

1. Sun, W.; Li, M.; Wu, M.; Hu, J. Uniformity of Si-containing diamond-like carbon films deposited at different positions by mesh hollow cathode discharge. Res. Phys. 2019, 14, 102480. [CrossRef] 
2. Konicek, A.R.; Grierson, D.S.; Sumant, A.V.; Friedmann, T.A.; Sullivan, J.P.; Gilbert, P.U.; Sawyer, W.G.; Carpick, R.W. Influence of surface passivation on the friction and wear behavior of ultra nanocrystalline diamond and tetrahedral amorphous carbon thin films. Phys. Rev. B 2012, 85, 155448. [CrossRef]

3. Ferreira, F.; Serra, R.; Cavaleiro, A.; Oliveira, J. Diamond-like carbon coatings deposited by deep oscillation magne-tron sputtering in Ar-Ne discharges. Diam. Relat. Mater. 2019, 98, 107521. [CrossRef]

4. Sui, X.; Liu, J.; Zhang, S.; Yang, J.; Hao, J. Microstructure, mechanical and tribological characterization of CrN/DLC/Cr-DLC multilayer coating with improved adhesive wear resistance. Appl. Surf. Sci. 2018, 439, 24-32. [CrossRef]

5. Imai, T.; Harigai, T.; Tanimoto, T.; Isono, R.; Iijima, Y.; Suda, Y.; Takikawa, H.; Kamiya, M.; Taki, M.; Hasegawa, Y.; et al. Hydrogen-free fluorinated DLC films with high hardness prepared by using T-shape filtered arc deposition system. Vacuum 2019, 167, 536-541. [CrossRef]

6. Choi, J.; Nakao, S.; Miyagawa, S.; Ikeyama, M. The effects of Si incorporation on the thermal and tribological properties of DLC films deposited by PBII\&D with bipolar pulses. Surf. Coat. Technol. 2007, 201, 8357-8361. [CrossRef]

7. Ding, H.; Fridrici, V.; Guillonneau, G.; Sao-Joao, S.; Geringer, J.; Fontaine, J.; Kapsa, P. Investigation on mechanical properties of tribofilm formed on Ti-6Al-4V surface sliding against a DLC coating by nano-indentation and micro-pillar compression techniques. Wear 2019, 432-433, 202954. [CrossRef]

8. Wang, X.; Sui, X.; Zhang, S.; Yan, M.; Yang, J.; Hao, J.; Liu, W. Effect of deposition pressures on uniformity, mechanical and tribological properties of thick DLC coatings inside of a long pipe prepared by PECVD method. Surf. Coat. Technol. 2019, 375, 150-157. [CrossRef]

9. Lan, R.; Ma, Z.; Wang, C.; Lu, G.; Yuan, Y.; Shi, C. Microstructural and tribological characterization of DLC coating by in-situ duplex plasma nitriding and arc ion plating. Diam. Relat. Mater. 2019, 98, 107473. [CrossRef]

10. Zhang, Y.; Zhang, S.; Sun, D.; Yang, G.; Gao, C.; Zhou, C.; Zhang, C.; Zhang, P. Wide adaptability of Cu nano-additives to the hardness and composition of DLC coatings in DLC/PAO solid-liquid composite lubricating system. Tribol. Int. 2019, 138, 184-195. [CrossRef]

11. Yang, X.D.; Saito, T.; Nakamura, Y.; Kondo, Y.; Ohtake, N. Mechanical properties of DLC films prepared inside of micro-holes by pulse plas-ma CVD. Diam. Relat. Mater. 2004, 13, 1984-1988. [CrossRef]

12. Türkmen, D.; Dettenrieder, C.; Forsberg, P.; Mattsson, A.; Nikolajeff, F.; Österlund, L.; Karlsson, M.; Mizaikoff, B. Corrosion detection by infrared attenuated total reflection spectroscopy via diamond-like carbon-coated silicon wafers and iron-sensitive dyes. Sensors 2019, 19, 3373. [CrossRef] [PubMed]

13. Petereit, B.; Siemroth, P.; Schneider, H.-H.; Hilgers, H. High current filtered arc deposition for ultra thin carbon overcoats on magnetic hard disks and read-write heads. Surf. Coat. Technol. 2003, 174-175, 648-650. [CrossRef]

14. Sun, Z.; Zhao, W.; Kong, D. Microstructure and mechanical property of magnetron sputtering deposited DLC film. J. Wuhan Univ. Technol. Sci. Ed. 2018, 33, 579-584. [CrossRef]

15. Li, H.; Wang, Q.; Zhuang, M.; Wu, J. Characterization and residual stress analysis of TiN/TiCN films on AZ31 magnesium alloy by PVD. Vacuum 2015, 112, 66-69. [CrossRef]

16. Ahmad, I.; Maguire, P.; Lemoine, P.; Roy, S.; McLaughlin, J. Deposition of carbon films onto metal and silicon substrates by filtered cathodic vacuum arc, plasma enhanced CVD and unbalanced magnetron sputtering. Diam. Relat. Mater. 2004, 13, 1346-1349. [CrossRef]

17. Geretovszky, Z.; Szörényi, T. Compositional and thickness distribution of carbon nitride films grown by PLD in the target plane. Thin Solid Film. 2004, 453-454, 172-176. [CrossRef]

18. Cai, F.; Zhang, J.; Wang, J.; Zheng, J.; Wang, Q.; Zhang, S. Improved adhesion and erosion wear performance of CrSiN/Cr multi-layer coatings on Ti alloy by inserting ductile Cr layers. Tribol. Int. 2021, 153, 106657. [CrossRef]

19. Ju, H.; Xu, J. Microstructure and tribological properties of $\mathrm{NbN}-\mathrm{Ag}$ composite films by reactive magnetron sput-tering. Appl. Surf. Sci. 2015, 355, 878-883. [CrossRef]

20. Li, H.; Rong, S.; Sun, P.; Wang, Q. Microstructure, residual stress, corrosion and wear resistance of vacu-um annealed TiCN/TiN/Ti films deposited on AZ31. Metals 2017, 7, 5. [CrossRef]

21. Xu, F.; Luo, L.; Xiong, L.; Liu, Y. Microstructure and corrosion behavior of $\mathrm{ALD} \mathrm{Al}_{2} \mathrm{O}_{3}$ film on AZ31 magnesium alloy with different surface roughness. J. Magnes. Alloy. 2020, 8, 480-492. [CrossRef]

22. Lopes, B.B.; Rangel, R.C.; Antonio, C.A.; Durrant, S.F.; Cruz, N.C.; Rangel, E.C. Mechanical and tribological properties of plasma deposited a-C:H:Si:O films. In Nanoindentation in Materials Science; Nemecek, J., Ed.; IntechOpen: London, UK, 2012 ; pp. 179-202.

23. Modabberasl, A.; Kameli, P.; Ranjbar, M.; Salamati, H.; Ashiri, R. Fabrication of DLC thin films with improved diamond-like carbon character by the application of external magnetic field. Carbon 2015, 94, 485-493. [CrossRef]

24. Conceição, K.; de Andrade, V.M.; Trava-Airoldi, V.J.; Capote, G. High antibacterial properties of DLC film doped with nanodiamond. Surf. Coat. Technol. 2019, 375, 395-401. [CrossRef]

25. Ilic, E.; Pardo, A.; Suter, T.; Mischler, S.; Schmutz, P.; Hauert, R. A methodology for characterizing the electrochemical stability of DLC coated interlayers and interfaces. Surf. Coat. Technol. 2019, 375, 402-413. [CrossRef]

26. Panjan, P.; Drnovšek, A.; Gselman, P.; Čekada, M.; Panjan, M.; Bončina, T.; Kek Merl, D. Influence of growth defects on the corrosion resistance of sput-ter-deposited TiAlN hard coatings. Coatings 2019, 9, 511. [CrossRef]

27. Scendo, M.; Staszewska-Samson, K. Effect of temperature on anti-corrosive properties of diamond-like carbon coating on S355 Steel. Materials 2019, 12, 1659. [CrossRef] 
28. Shi, K.; Zhang, Y.; Zhang, J.; Xie, Z. Electrochemical properties of niobium coating for biomedical appli-cation. Coatings 2019, 9, 546. [CrossRef]

29. Hao, E.; An, Y.; Liu, X.; Wang, Y.; Zhou, H.; Yan, F. Effect of annealing treatment on microstructures, mechanical properties and cavita-tion erosion performance of high velocity oxy-fuel sprayed NiCoCrAlYTa coating. J. Mater. Sci. Technol. 2020, 53, 19-31. [CrossRef]

30. Liu, Y.; Erdemir, A.; Meletis, E.I. Influence of environmental parameters on the frictional behavior of DLC coatings. Surf. Coat. Technol. 1997, 94-95, 463-468. [CrossRef]

31. Shaha, K.P.; Pei, Y.T.; Chen, C.Q.; de Hosson, J.T. Pulsed DC sputtered DLC based nanocomposite films: Controlling growth dynamics, microstructure and frictional properties. Mater. Technol. 2011, 26, 15-19. [CrossRef]

32. Li, G.; Xu, Y.; Xia, Y. Effect of Cr atom plasma emission intensity on the characteristics of Cr-DLC films deposited by pulsed-DC magnetron sputtering. Coatings 2020, 10, 608. [CrossRef] 